\title{
Colaboração Posta em Circulação: Etiqueta Vazia em Práticas Discursivas Educacionais?
}

\author{
Collaboration Put to Work: \\ Empty Label on Educational Discursive Practices?
}

\section{Elaine Fernandes MATEUS* Larissa PICONI** Michele Salles EL KADRI***}

Resumo: É no contexto da reorganização do novo capitalismo no início deste século, que os conceitos de 'rede', 'parceria' e 'colaboração', ligados à busca de formas de gerenciamento da vida social (FAIRCLOUGH, 2003), têm se consagrado nas mais diversas formações discursivas, dentre as quais, a educacional. A profusão de usos e de sentidos a eles associados leva-nos, neste estudo, à indicação de 'colaboração' como termo candidato à fórmula, uma entidade que apaga o protagonismo humano. Com interesse específico nos usos de 'colaboração' no campo da formação de professores, analisamos o estatuto formuláico do termo com base em Krieg-Planque (2010) e na análise do discurso de linha francesa. Para tanto, concentramo-nos na investigação de resumos e/ou no título das teses de doutorado desenvolvidas

* Doutorado em Linguística Aplicada e Estudos da Linguagem pela Pontifícia Universidade Católica de São Paulo (2005). Professora adjunta do Departamento de Letras Estrangeiras Modernas da Universidade Estadual de Londrina. Contato: mateus@uel.br.

** Técnica em Assuntos Educacionais da Universidade Tecnológica Federal do Paraná. Especialista em Comunicação e Semiótica, pela Faculdade Maringá (2006). Mestre em Estudos da Linguagem pela Universidade Estadual de Londrina (2009). Doutoranda em Estudos da Linguagem pela mesma instituição. Contato: larypiconi@yahoo.com.br. *** Mestre em Estudos da Linguagem pela Universidade Estadual de Londrina (2010). Doutoranda em Estudos da Linguagem pela mesma instituição, com estágio na Griffith University, Queensland, Australia. Bolsista da CAPES, processo 5726/11-5. Contato: misalles@yahoo.com.br. 
no Brasil de 2005 a 2010, disponibilizadas pelo Banco de Teses da CAPES. Os resultados revelam que as zonas de cristalização discursiva circulantes no discurso acadêmico favorecem o esvaziamento do termo que decorre da ausência de definição, de sua ambiguidade e da dispersão de sentidos, contribuindo para o domínio da ordem social do novo capitalismo e para a legitimação do senso comum.

Palavras-chave: Colaboração. Fórmula. Formação de professores.

Abstract: It is in the context of the reorchestration of the new capitalism at the beginning of this century that the concepts of 'network', 'partnership' and 'collaboration', associated with a search for ways of managing social life (FAIRCLOUGH, 2003), are consecrated in a variety of discursive formations, being the educational one of them. The profusion of uses and meanings associated with the term 'collaboration' makes us indicate 'collaboration' as a possible formula, an entity that blurs human protagonism. With specific interest in the uses of 'collaboration' in the teacher education area, we analyse the formulaic status of the term based on Krieg-Planque (2010) and on the French tradition of discourse analysis. We do so by investigating abstracts and/or titles of thesis published between 2005 and 2010 and available at CAPES database. Results show that the zones of discursive crystallization present in the academic discourse favor the emptiness of the term, due to lack of definition, ambiguity and dispersion of senses, contributing to the hegemonic social order of the new capitalism and to the common sense legitimation.

Key-words: Collaboration. Formula. Teacher education.

\section{Introdução}

O termo 'colaboração' e suas variações mostram-se cada vez mais presentes nos diversos campos discursivos: no corporativo, a exemplo de empresas chamando seus funcionários de 'colaboradores'; no acadêmico, com um crescente número de pesquisas intituladas 'colaborativas'; no político, com os regimes de colaboração e cooperação entre países, Estados e Municípios; no meio virtual, em redes colaborativas desenvolvidas para objetivos diversos. Em julho de 2011, o número de ocorrências deste termo no Google passava de 16 milhões, sem contar as variantes 'colaborativo' e 
'colaborativa' que, somadas, ultrapassavam a casa dos 14 milhões de ocorrências.

Um levantamento preliminar sobre a presença do termo 'colaboração' em pesquisas educacionais, realizado pelos membros do grupo de pesquisa Aprendizagem sem fronteiras: linguagem, ética e formação de professores, em 2010/ 2011, possibilitou a percepção de que há vários entendimentos do que seja 'colaboração' e de que essa profusão de usos, ao mesmo tempo em que significa alguma coisa para todos, significa coisas diferentes transformadas, por vezes, em coisa alguma. Estas zonas de cristalização discursiva circulantes no discurso acadêmico tendem ao esvaziamento de sentidos e à esterilidade da ação. É deste "olhar atento", como indica Krieg-Planque (2010), que decorre a indicação de 'colaboração' como termo candidato a fórmula, definida por esta francesa, analista do discurso, como palavras (ou sintagmas) que, mobilizadas massivamente em um conjunto de práticas linguageiras em um momento e espaço público dado, adquirem um estado de relativa cristalização evidenciando uma dispersão de sentidos.

Daí nosso interesse por compreender de que modos o termo 'colaboração' tem sido abordado no campo da educação, mais particularmente da educação de professores, e posto em circulação nos relatos de pesquisa de doutoramento, nos últimos anos. Este trabalho, que parte de um projeto de pesquisa intitulado Ensino colaborativo e aprendizagem de professores, insere-se, deste modo, no espaço discursivo de formação de professores, e objetiva analisar o estatuto formuláico do termo 'colaboração' a partir do estudo dos corpora selecionado.

Para tanto, analisamos quarenta e oito resumos de teses de doutorado desenvolvidas no Brasil, de 2005 a 2010, disponibilizadas pelo Banco de Teses da CAPES (Coordenação de Aperfeiçoamento de Pessoal de Nível Superior) a fim de circunscrever o termo 'colaboração' como objeto fórmula por meio de suas principais propriedades, a saber: seu caráter cristalizado, seu caráter discursivo, seu caráter de referente social e seu caráter polêmico (KRIEG-PLANQUE, 2010).

Para a seleção do corpus, elegemos as teses desenvolvidas na área da educação e de formação de professores que apresentavam o termo 'colaboração' e/ou seus derivados 'colaborativo(a)' em lugar de destaque nos resumos, nos títulos e/ou palavras-chave.

A importância de se investigar 'colaboração' a partir do seu caráter formuláico encontra-se na possibilidade de aprofundamento dos significados 
a ela dados e de descoberta de sentidos que circulam na sociedade. Em outras palavras, encontra-se na possibilidade de circunscrever os sentidos que este termo carrega e os sentidos que ele é capaz de criar. Este artigo estrutura-se a partir da discussão dos pressupostos da noção de fórmula segundo Krieg-Planque (2010). Em seguida, analisamos a emergência da fórmula 'colaboração' nas teses de doutorado por meio de sua vinculação às quatro propriedades do conceito de fórmula. Por fim, tecemos considerações quanto às suas implicações para a formação de professores.

\section{A Noção de Fórmula na Perspectiva da Análise do Discurso Francesa}

A noção de fórmula foi recentemente desenvolvida por Krieg-Planque (2010) e circunscreve-se dentro de um contexto de formulações e reformulações da Análise do Discurso Francesa. São ainda poucos e recentes os trabalhos que se propõem ao estudo de fórmulas tanto em contexto internacional como nacional.

Com sua origem na França, na década de 60, a Análise do Discurso (AD) surge em um espaço marcado por discussões sobre marxismo e política compartilhadas por Jean Dubois, linguista, e Michel Pêcheux, filósofo, os quais tinham nas suas agendas aspectos como a luta de classe, história e movimento social. Nesse contexto, a AD surge na tentativa de se estabelecer como um dispositivo teórico-metodológico capaz de estudar a linguagem/ discurso na sua complexa e viva relação com o contexto de sua produção, imbuída de dimensões políticas, históricas e sociais que os constituem e por elas são constituídos (PARDO-ABRIL, 2007).

Desde o seu surgimento, a AD tem se consolidado em função de seus contornos constantemente redefinidos e reformulados pelas análises e analistas que vão criando e recriando suas bases.

A AD nunca foi/é/será a mesma, é sempre uma disciplina em constante reformulação - que exige novos métodos, novos dispositivos e novas reflexões justamente porque as sociedades e a história estão em movimento, e, por conseguinte, os discursos também estão. (VOSS, 2011, p. 16).

Nesse contexto, Maingueneau (2007) revisita o conceito de formação discursiva bastante retomado no campo da Análise do Discurso. Segundo 
ele, "na análise do discurso francófona, a noção de "formação discursiva", a mais antiga, coexiste com outras como as de "posicionamento" e "gênero de discurso", sem que muitas vezes sua articulação - e mesmo sua compatibilidade - seja realmente explicitada" (MAINGUENEAU, 2007, p. 20). Frente a isso, ele distingue duas unidades com as quais os analistas dos discursos lidam: unidades tópicas e não tópicas. Compreendem as unidades tópicas espaços já "pré-delineados" pelas práticas verbais (as unidades territoriais), os quais englobam tipos de discurso e os gêneros de discurso e, ainda, unidades transversais, que se referem a registros definidos a partir de critérios linguísticos, funcionais e comunicacionais que atravessam textos em múltiplos gêneros do discurso.

A unidades não tópicas, por sua vez, caracterizam-se por sua não territorialidade, já que se situam em enunciados profundamente inscritos na história e, construídas pelo pesquisador, independem de fronteiras preestabelecidas. Constituem unidades não tópicas: formação discursiva e percurso.

\begin{tabular}{|l|l|l|l|}
\hline \multicolumn{2}{|c|}{ Unidades tópicas } & \multicolumn{2}{c|}{ Unidades não tópicas } \\
\hline Terrotoriais & Transversas & \multicolumn{1}{|c|}{$\begin{array}{l}\text { Formações } \\
\text { discursivas }\end{array}$} & Percursos \\
\hline $\begin{array}{l}\text { Tipo/ Gêneros de discurso } \\
\text { a)Genêros de campos } \\
\text { b) Gêneros de aparelhos }\end{array}$ & $\begin{array}{l}\text { Registros Linguísticos } \\
\text { Registros Funcionais } \\
\text { Registros comunicacionais }\end{array}$ \\
\hline
\end{tabular}

Fonte: Maingueneau (2007, p. 33).

Ao categorizar e diferenciar as unidades tópicas e não tópicas, Maingueneau ressignifica o conceito de formação discursiva ao distingui-la das noções de posicionamento e gêneros, a partir do critério de territorialidade, discriminando unidades que, por vezes, são tratadas indistintamente. Nesse sentido, ele nomeia formação discursiva as unidades que não podem ser delimitadas por fronteiras que não sejam as estabelecidas pelo pesquisador e devem ser especificadas historicamente. 
Para Maingueneau (2008c), posicionamento e formação discursiva são unidades diferentes, na medida em que uma, o posicionamento, está estreitamente vinculada a instituições e a outra, a formação discursiva, não possui uma instituição como referência. Por isso, o posicionamento é uma unidade tópica territorial, presa a instituições e tipos e gêneros do discurso, e a FD é uma unidade não-tópica. (VOSS, 2011).

A noção de percurso constitui também uma unidade não tópica de Análise do Discurso e caracteriza-se como o movimento de elementos extraídos de diversas ordem do interdiscurso, tais como palavras, grupos de palavras, frases, fragmentos de textos com o objetivo de "desestruturar as unidades instituídas por meio da definição de percursos inesperados: a interpretação se apóia, assim, sobre a explicitação de relações imprevistas no interior do interdiscurso" (MAINGUENEAU, 2007, p. 33).

As análises das fórmulas apresentam-se, então, como potenciais para o estudo de percurso já que possibilitam descrever laços insuspeitos no interdiscurso que "ao mesmo tempo diferenciam o uso da fórmula e a tornam um lugar comum para um grupo de locutores” (VOSS, 2011, p. 18) Voss (2011, p. 18) coloca, ainda que

[...] imaginamos que uma pesquisa sobre os percursos de uma fórmula dispersa possa nos oferecer resultados interessantes sobre as relações entre língua, sentido e história, já que, ao invés de focalizar aspectos intrinsecamente históricos eideológicos, como talvez faria uma pesquisa em torno de uma FD (no sentido dado por Maingueneau [2008c] para este conceito), uma pesquisa investida nos percursos e trajetos de uma fórmula pode relacionar fatores linguísticos (como a cristalização da fórmula em um significante relativamente estável) a fatores históricos (os campos ideológicos ou de saberes que autorizam os sentidos da fórmula no discurso) e também a fatores pragmáticos (como sobre as determinações da cena enunciativa sofridas pela fórmula em circulação).

Nesse contexto, apoiamo-nos no conceito de fórmula segundo a perspectiva de Krieg-Planque (2010). Para a autora 'a noção de fórmula em análise do discurso' trata de uma questão tanto do ponto de vista teórico quanto metodológico e designa 
... um conjunto de formulações que, pelo fato de serem empregadas em um momento e em um espaço público dados, cristalizam questões políticas e sociais que essas expressões contribuem, ao mesmo tempo, para construir. (KRIEG-PLANQUE, 2010, p. 9).

Portanto, a partir da definição de Krieg-Planque, salientamos primeiramente que a gênese de uma fórmula está em razão do seu uso. Isso quer dizer que não existe fórmula em si, ou seja, não é possível que uma palavra seja considerada fórmula por suas propriedades semântico-lexicais exclusivamente. A condição de fórmula de uma palavra só pode existir em "um conjunto de práticas linguageiras e de relações de poder e de opinião, em um momento dado, em um espaço público dado [...]" (KRIEG-PLANQUE, 2010, p. 14).

Isso implica o reconhecimento de que a gênese de uma fórmula nem sempre coincide com a gênese da palavra. Tomemos como exemplo o termo objeto deste estudo, 'colaboração', que, apesar de existir e de integrar a língua portuguesa há muitos anos, somente a partir do início desse século é retomado massivamente e tem seu espaço de circulação ampliado em diferentes esferas discursivas - aspecto este que será explorado adiante. Nesse sentido, identificar a condição de fórmula da palavra 'colaboração' e de suas variantes só é possível por meio da investigação da história do uso dessa palavra, a partir do momento que se tornou notável. A gênese da fórmula está diretamente relacionada ao começo de sua circulação.

A circulação constitui um segundo pressuposto para a compreensão da fórmula, uma vez que, circulando, uma fórmula pode passar de uma língua a outra, mudar de lugar de emergência de formação discursiva e, no interior de uma mesma língua, adquirir produtividade lexicológica. Ela passa, assim, a constituir um denominador comum e não resulta apenas de uma mecânica do linguístico, mas "de práticas linguageiras e de relações de poder e de opinião que se observa na discursividade” (KRIEG-PLANQUE, 2010, p. 43). Essa circulação, portanto, não é aleatória. O emprego das fórmulas é sustentado por acontecimentos ou por outros discursos que mobilizam a sua recorrência. O percurso e a utilização das fórmulas são potencializados / constrangidos por contextos sócio-históricos e formações ideológicas que motivam o seu emprego pelos locutores, que lhe imprimem um caráter conflituoso e problemático. 
Os muitos sentidos mobilizados na circulação das fórmulas fazem com que nenhum significado se mantenha, tornando-se difícil apreendê-lo. Deste modo, a fórmula é marcada como um termo de consenso que é muito falado, mas pouco definido. Petiot (1990 apud KRIEG-PLANQUE, 2010 , p. 26) definiu esse processo como "evaporação da significação" comparando-o como uma etiqueta vazia, "um significante reivindicado por todos, cujo(s) significado(s) seria(m) indefinível(is), pois inacessível(is)".

No entanto, apesar desse movimento contínuo de redefinição de sentidos, as fórmulas se caracterizam como tal por sua cristalização, uma vez que são "formalmente delimitáveis e relativamente estáveis do ponto de vista da descrição linguística que delas se pode fazer" (KRIEG-PLANQUE, 2010, p. 14).

A cristalização dá-se tanto na estabilidade do significante da fórmula que a sustenta nos debates públicos, quanto no processo de cristalização que ela promove sobre esses debates. "Em outros termos, a língua é atuante por sua cristalização. É na interrupção da extensão da combinatória ou, em outras palavras, na cristalização, que o discurso é ação" (KRIEG-PLANQUE, 2010, p. 45).

Jean Pierre Faye, em seu estudo da fórmula 'Estado Total', evidenciou que a capacidade de ação da fórmula tem como efeito tornar alguma coisa aceitável. Nesse sentido, a cristalização como anúncio da "consagração da palavra como questão política” (KRIEG-PLANQUE, 2010, p. 45) tornase um instrumento poderoso. Para Fairclough (2003), a representação de palavras como entidades contribui para legitimar políticas e produzir impressão de consenso.

No entanto, é justamente no fato de se impor como dominante que reside a característica constitutivamente polêmica da fórmula.

Diante do exposto, abordamos os aspectos necessários para que a palavra assuma a condição de fórmula, tendo por base os pressupostos apresentados e tratamos a análise do termo 'colaboração' no contexto das teses desenvolvidas na área de formação de professores, a fim de desenhar as suas características enquanto fórmula. 


\section{A Emergência da Fórmula Colaboração nas Pesquisas Educacionais Desenvolvidas no Brasil entre o Período de 2005 a 2010: o caráter gradual de suas propriedades}

Para fins desta pesquisa, observamos a possível elevação do termo 'colaboração' à condição de fórmula a partir dos resumos e/ou dos títulos de teses de doutorado desenvolvidas no Brasil, disponibilizadas no Banco de Teses da CAPES, buscando evidenciar o seu processo de cristalização. Como recorte, utilizamos os trabalhos no campo educacional que contêm o termo 'colaboração' e/ou variantes (colaborativo/colaborativa) incorporados no título e/ou no resumo e/ou nas palavras-chave, desenvolvidos no período de 2005 a 2010. A partir da nossa inserção em contextos de pesquisa na área de formação de professores, apresentamos possíveis aspectos que se mostraram favoráveis para a emergência da ‘colaboração' como fórmula. No âmbito político, econômico e social, sinalizamos a transformação nos modos de produção capitalista e, na esfera educacional, a disseminação e difusão da abordagem vygotskiana (1978, 1997, 1998, 1999) para o desenvolvimento humano.

Ao longo das últimas cinco décadas, o capitalismo enfrentou inúmeras crises e viu-se diante da constante necessidade de reformulação de suas práticas. Nesse processo, as sociedades reestruturaram os modos de produção e consumo com base nos modelos tipo taylorista/fordista e toyotista. Mais recentemente, com o advento tecnológico da rede mundial de computadores, a crescente implantação de empresas transnacionais e a proliferação mercados em rede, as mudanças sociais na chamada era da "globalização", da "cultura do consumo", do "novo capitalismo" (FAIRCLOUGH, 2003, p. 4) consolidam-se com vistas a uma maior participação da classe trabalhadora na concepção, programação e avaliação dos resultados de suas próprias tarefas, bem como propostas que valorizam o trabalho em equipe. Esse novo papel para os empregados não é fortuito, mas fundamenta-se nos pressupostos de que os trabalhadores são elementos-chave da rentabilidade e competitividade da empresa e de que, sem a sua cooperação e compromisso, é impossível aumentar a produtividade e melhorar a competitividade no mercado de capitais.

Nesse contexto, a colaboração e cooperação entre empresas e indivíduos, trabalho em equipe, estabelecimento de parcerias aparecem como palavras/expressões-chave, essenciais à manutenção das sociedades na lógica do novo capitalismo. 
Na esfera educacional, ‘colaboração’ vem ancorada em pesquisas que situam seus autores num dado lugar discursivo genericamente definido como sócio-histórico-cultural, a partir do qual proferem seus entendimentos sobre o desenvolvimento humano.

Fundamentados nos estudos de Vygotsky (1978; 1997; 1998; 1999) e de seus colaboradores, pesquisadores contemporâneos se voltam ao entendimento da cognição em relação ao envolvimento dos sujeitos em práticas sociais, mediadas pela cultura e situadas nos espaços históricos (por exemplo, Hasan (mimeo); Cole; Engeström, 1993; Engeström, Y., 1994, 2002; Engeström, R., 1995; Cole, 1996; John-Steiner, 2000; Holzman, 2002; Rogoff, 2003; Cheyne; Tarulli, 2004; para citar alguns).

Assim, a cognição deixa de ser tratada como um processo na mente do ser humano, desvinculado da relação que este estabelece com o mundo que o cerca, e passa a ser analisada como forjada no processo de produção da própria existência humana, por meio da ressignificação feita pelo sujeito dos conhecimentos já existentes no plano social. Essa ressignificação é mediada pela relação do indivíduo com o outro, pela transmissão dos conhecimentos historicamente acumulados por meio da linguagem e de outros signos e instrumentos que são criados e modificados coletivamente no curso da história, sendo isto possível pela atividade. Esta atividade, portanto, não é isolada. Ela é essencialmente social e, assim, prescinde do trabalho com o outro.

Esta epistemologia tem repercutido nos debates educacionais. O aprendizado nesse contexto é entendido não mais como um processo individualizado, mas constitutivamente social. Concepções desta natureza trazem consigo diferentes papéis para a escola, para os professores e alunos, além de repercutirem nas tendências pedagógicas e nas metodologias de ensino.

Ainda que breve, este contexto amplo da sociedade atual permite compreender algumas razões e explicitar possíveis condições de emergência da cristalização da 'colaboração' como fórmula. A seguir, buscamos evidenciar, por meio da análise das 48 teses selecionadas para este estudo, seu caráter de fórmula a partir dos critérios de cristalização, discursividade, referência social e polemicidade da 'colaboração', conforme descritos em Krieg-Planque (2010). 


\subsection{O caráter cristalizado da fórmula}

Em relação à sua primeira propriedade, é interessante ressaltar que Krieg-Planque (2010) entende que a fórmula é sustentada por uma forma significante relativamente estável e que ela pode ser tanto uma unidade lexical simples quanto uma unidade lexical complexa (unidade léxico-sintática ou sequência autônoma (frase)).

Quanto à sua natureza, a cristalização pode ser de ordem estrutural (ou formal) e de ordem memorial, sendo a primeira relacionada nos termos da língua e nas categorias da gramática e a segunda relacionada ao conjunto de enunciados que circulam 'em bloco' num dado momento e que são percebidos como formando um todo, cuja origem é irrecuperável. Para a autora, esta distinção é adequada por existir um continuum entre as duas ordens de cristalização, que se liga ao engendramento mútuo da língua e do discurso. Em relação ao grau, uma sequência cristalizada é mais ou menos cristalizada de acordo com os critérios semânticos (não composicionalidade do sentido), critérios sintáticos (inseparabilidade, comutação, repetição parcial, explicitação de denominador comum). Além disso, Krieg-Planque enfatiza que, apesar da fórmula se identificar com uma materialidade linguística particular, a atitude que preside a análise de uma fórmula não deve ser de formalismo absoluto, e que, portanto, ela pode ter variantes. As análises mostraram que a fórmula em questão passa por um processo de transformação de unidade lexical simples para uma unidade lexical complexa como evidência do seu próprio processo de cristalização. Esta mudança não é aleatória.

Nos resumos em que a unidade lexical ‘colaboração' aparecia, quase sempre estavam presentes também suas variantes, as quais, por vezes, passaram a ser mais retomadas nos enunciados do que 'colaboração'. No corpus analisado, a unidade lexical simples foi mobilizada 46 vezes, enquanto o termo na sua forma adjetivada (colaborativo/colaborativa) teve 146 ocorrências. Diferentes sintagmas apareceram: processo colaborativo; aprendizagem colaborativa; produção colaborativa; atividades instrucionais colaborativas; diálogo colaborativo; reflexões colaborativas; relacionamentos colaborativos; equipes técnicas colaborativas; espaço de trabalho virtual colaborativo; sistemas colaborativos; trabalho colaborativo; cursos on-line colaborativo; ambiente colaborativo; grupos colaborativos; estratégias colaborativas; dinâmica colaborativa; arranjos colaborativos; práticas colaborativas; saberes colaborativos. 
As unidades lexicais complexas trazidas acima, formadas por sintagmas nominais com o adjetivo denominal (colaborativo(s)/ colaborativa(s)), favorecem, segundo Krieg-Planque (2010), a cristalização, assim como acontece com as nominalizações, por sua ambiguidade e subdeterminação. Como a autora mesma explica:

... o adjetivo denominal é o lugar de uma ambiguidade por meio do qual se deixa à apreciação de interpretações diversas a natureza da relação que se estabelece (ou então, o que não se estabelece) entre nome subjacente ao adjetivo e o nome regente. (KRIEG-PLANQUE, 2010, p. 77).

A diversidade e a multiplicidade de unidades lexicais que carregam a multiplicidade de unidades lexicais a que se vem juntar uma adjetivação sintética ou analítica são indicativos da multiplicidade de sentidos mobilizados por essa palavra que circulam a partir da sua cristalização de ordem memorial, não sendo possível recuperar a origem desses fragmentos em bloco.

Nesse sentido, a criação, formulação e reformulação de unidades lexicais complexas compostas pelos adjetivos 'colaborativo(s)/colaborativa(s)' trabalham para a consolidação da unidade lexical simples 'colaboração' como fórmula cristalizada.

Porém, a análise a partir da sua dimensão discursiva é necessária para a compreensão da mobilização de tantos sintagmas distintos para sua cristalização.

\section{$2.2 \mathrm{O}$ caráter discursivo da fórmula}

Conforme Krieg-Planque (2010), apesar de a fórmula possuir uma materialidade linguística, a noção de fórmula não é uma noção linguística, mas sim uma noção discursiva. Portanto, não é uma forma nova que o analista deve buscar, mas sim um uso particular, ou uma série de usos particulares, por meio dos quais a sequência assume um movimento, é retomada, é comentada e "para" de funcionar no modo "normal".

Considerando o escopo deste texto e o corpus analisado, destacamos a dimensão discursiva da fórmula analisada no campo discursivo educacional. No entanto, reconhecemos a necessidade de análise do percurso da ‘colaboração' perpassando diferentes campos discursivos, a fim de caracterizar de modo mais abrangente o caráter formuláico do termo. 
A recorrência de 'colaboração' e suas variações no corpus analisado foi constantemente retomada nos resumos que mobilizavam o discurso das Tecnologias de Informação e Comunicação. A unidade lexical complexa "aprendizagem colaborativa" destaca-se nesses trabalhos, conforme ilustra o excerto seguinte.

(1)

Este problema de pesquisa relacionou-se à investigação dos aspectos pedagógicos e tecnológicos implicados na aprendizagem colaborativa mediada pela conferência e chat. A investigação esteve atrelada a uma perspectiva integradora da pedagogia à tecnologia, rompendo com as abordagens tecnicistas que enfatizam apenas os componentes tecnológicos em ambientes de aprendizagem na internet. [...] Os resultados permitiram concluir que a tecnologia da conferência propiciou uma colaboração quantitativamente e qualitativamente distinta daquela propiciada pela tecnologia do chat. (VILLALOBOS, 2007)

O trecho anterior reitera a relação entre as tecnologias e a educação. Percebe-se que posicionamentos discursivos divergentes que circulam no campo pedagógico são mobilizadas. São elas: abordagem tecnicista e abordagem integradora. $\mathrm{Na}$ frase "A investigação esteve atrelada uma perspectiva integradora da pedagogia à tecnologia, rompendo com as abordagens tecnicistas que enfatizam apenas os componentes tecnológicos em ambientes de aprendizagem na internet...”, evidencia-se uma definição de limites entre elas, de modo que a abordagem tecnicista é definida e retomada para afirmar o que a abordagem integradora não é, no caso, aquela que enfatiza apenas os componentes tecnológicos.

A variante 'aprendizagem colaborativa' é retomada como elemento que trabalha para o estabelecimento dos limites entre um posicionamento e outro, de modo a negar a abordagem tecnicista para afirmar a perspectiva integradora. Esse movimento acontece pelo caráter desumanizado da perspectiva tecnicista desenhado a partir do advérbio de exclusão 'apenas' em (abordagens tecnicistas que enfatizam apenas os componentes tecnológicos em ambientes de aprendizagem na internet). Em oposição, a variante 'colaborativa' trabalha para caracterizar aspectos tecnológicos, no 
caso conferência e chat, como ferramentas tecnológicas que favorecem a interação entre pessoas, caracterizando a pessoalidade nas tecnologias.

A análise de trabalhos que mobilizam a fórmula 'colaboração' para tratar de tecnologias na educação evidencia o seu papel fundamental nesse espaço discursivo. O desenvolvimento tecnológico na sociedade atual tem impactado significativamente os modos de vida atuais. A área da educação, circunscrita nesse contexto, tem absorvido, resistido e sido modificada a partir do desenvolvimento das novas tecnologias. A exemplo disso, o ensino a distância, regulamentado no contexto brasileiro no final da década de 90, tem expandido e divido espaços com a educação presencial.

A educação formal historicamente se estabeleceu e se consolidou nos papéis sociais do professor e aluno como protagonistas do processo. Com a inserção das tecnologias na educação, os componentes tecnológicos são destacados enquanto os sujeitos saem da centralidade do processo, como visto no resumo analisado em que a aprendizagem e os aspectos pedagógicos são trazidos em termos de recursos tecnológicos exclusivamente (relacionou-se à investigação dos aspectos pedagógicos e tecnológicos implicados na aprendizagem colaborativa mediada pela conferência e chat).

Os termos 'colaboração' e 'colaborativo', frequentemente evocados nos discursos das TICs no campo da educação, trabalham para construção da ideia da pessoalidade, do envolvimento de pessoas, nos processos de aprendizagem mediada pelo computador. No entanto, ao mobilizar colaboração em "Os resultados permitiram concluir que a tecnologia da conferência propiciou uma colaboração quantitativamente e qualitativamente distinta daquela propiciada pela tecnologia do chat", mantém-se a impessoalidade do processo uma vez que não se explicita a colaboração entre quem, apagando os sujeitos da colaboração. A nominalização ("uma colaboração") reitera o processo de cristalização da fórmula, uma vez que se pretende significar algo já sabido e conhecido por todos.

O discurso da ‘colaboração' junto ao discurso das “TICs” trabalham para minimizar as noções de impessoalidade e a individualidade que os processos de aprendizagem mediados pelo computador podem suscitar. A fórmula, nesse contexto, opera produzindo a ideia de um processo pessoal ao invés de computadorizado e que se dá coletivamente, ao invés de individualmente.

No corpus, evidenciamos outros aspectos do caráter discursivo da fórmula analisada. Este apareceu em diversas áreas do conhecimento em 
que as teses analisadas eram situadas, trazendo indícios do seu estatuto enquanto referente social.

\section{$2.3 \mathrm{O}$ caráter referente social da fórmula}

A fórmula se constitui como referente social, o que pode ser entendido como sendo seu aspecto dominante, num dado momento e num dado espaço sociopolítico. Isso não quer dizer que a significação de que a fórmula é investida seja homogênea. Ao contrário: suas significações são múltiplas e, às vezes, contraditórias; aspectos estes que se mostram na análise que fazemos do termo 'colaboração'. Falar do caráter referente social da fórmula implica dizer que ela é um signo que evoca algo para todos em um dado momento. Nas palavras de Krieg-Planque, um signo notório. Tal notoriedade pode ser mostrada pelo aumento da frequência deste signo, observado ao longo do tempo num corpus estável.

Em busca no Banco de Teses da CAPES, evidenciou-se um aumento considerável de dissertações e teses que apresentam o termo 'colaboração' e seus derivados 'colaborativo(a)' em seus resumos nas múltiplas áreas do conhecimento nos últimos cinco anos.

\begin{tabular}{ccc}
\hline Ano & $\begin{array}{c}\text { Números de resumos que } \\
\text { contém o termo } \\
\text { colaborativo(a) }\end{array}$ & $\begin{array}{c}\text { Números de resumos } \\
\text { que contêm o termo } \\
\text { colaboração }\end{array}$ \\
\hline $\mathbf{2 0 0 5}$ & 36 & 130 \\
$\mathbf{2 0 0 6}$ & 39 & 141 \\
$\mathbf{2 0 0 7}$ & 45 & 149 \\
$\mathbf{2 0 0 8}$ & 57 & 183 \\
$\mathbf{2 0 0 9}$ & 68 & 199 \\
$\mathbf{2 0 1 0}$ & 74 & 226 \\
\hline
\end{tabular}

É, ainda, importante dizer que, em 1989, somente três (3) trabalhos foram localizados pelo sistema de busca do Banco de Teses da CAPES por conter o termo 'colaboração' no resumo. Dez anos mais tarde (1999), este 
número passa a quarenta e seis (46) e, em 2009, o número de trabalhos que apresentam a palavra 'colaboração' é de cento e noventa e nove (199).

Outro índice que demonstra o caráter notório da fórmula é a produtividade lexicológica, o que implica dizer que um signo é conhecido de todos e atestado em tipos variados de discurso. Ou seja, certas palavras e expressões de vocabulários especializados, mesmo que partilhem algumas propriedades próprias da fórmula (por exemplo, seu caráter polêmico e sua função de referente comum) só serão fórmulas se saírem do seu domínio para invadir o corpo social. Para caracterizar-se como uma fórmula, portanto, o signo deve ser encontrado nos mais variados tipos de discurso, sendo um denominador comum entre eles, uma passagem obrigatória. Sobre esta característica, já dissemos na introdução do texto, ao nos referirmos a sua presença nos mais diferentes campos e no volume de ocorrências reveladas pela busca no Google.

Nos quarenta e oito resumos analisados, além da constante retomada das TICs junto ao interdiscurso da colaboração, a unidade lexical 'colaboração' aparece constantemente evocada junto ao discurso da formação de professores. O sentido predominante dado ao termo é para designar uma atividade desenvolvida por grupos de pessoas ou, ainda, implica qualquer tipo de cooperação entre partes, o "fazer juntos" para mudar algo. Nota-se que, nestes trabalhos, há certo efeito de eufemismo, utilizado para evitar e apagar os conflitos. O termo está muito associado a uma questão harmônica, sem conflitos, romantizada.

(2)

Podemos afirmar que no grupo que investigamos aparecem diferentes possibilidades da transição do trabalho coletivo para o colaborativo e, entre elas, destacamos: os objetivos em comum dos formadores, a necessidade da troca de experiência e da discussão de conhecimentos didáticos específicos da área de Cálculo Diferencial e Integral, a busca de apoio para enfrentar as mudanças curriculares necessárias, o clima de camaradagem e confiança construído ao longo dos encontros, a busca de conhecimentos específicos do Cálculo Diferencial e Integral. (JUNIOR, 2006) 
Apesar dos diferentes sentidos mobilizados pela colaboração como fórmula, existe um denominador comum que atravessa as pesquisas analisadas: a colaboração como elemento necessário para a transformação de uma dada realidade. A partir dos excertos aqui apresentados, podemos exemplificar este movimento, evidenciado na retomada constante do discurso da colaboração como solução para algum problema levantado (e.g., a colaboração para o rompimento com as abordagens tecnicistas (excerto 1); a colaboração para produzir mudanças curriculares (excerto 2)). A relação entre colaboração como pressuposto de mudanças e transformações de uma dada realidade é demonstrada, ainda, nos excertos seguintes.

(3)

A ausência de colaboração entre ambas, por sua vez, teve como consequência a dificuldade de promover mudanças na prática e o desenvolvimento profissional da participante. (PAULA, 2010)

Os resultados mostram que a experiência de colaboração crítica aplicada em contexto virtual vivenciada pelos colaboradores abriu perspectivas ao desenvolvimento de um processo pedagógico virtual plural [...] comprometido com a transformação [...] (OLIVEIRA, 2009)

Os resultados evidenciam que a transformação da prática pedagógica é possível [...] desde que a escola reserve espaço às experiências de pertencimento e os professores em colaboração, identifiquem os desafios e os transformem em situações de aprendizagem, assumindo os riscos que esta atitude implica. (MOURA, 2006)

[...]demonstrar como a ação-colaborativa entre professores de língua inglesa (LI) em formação continuada e universidade pode produzir mudanças contextuais e localmente situadas no micro-mundo da sala de aula, quando possível e desejável. (OLIVEIRA, 2006)

No entanto, justamente por apresentar-se como aceita e necessária a todos, é que se instaura o caráter polêmico da fórmula. Fiala e Ebel, citados em Krieg-Planque (2010, p. 100), ressaltam que “o caráter polêmico da 
fórmula é indissociável do fato de que ela constitui um referente social: é porque há um denominador comum, um território partilhado, que há polêmica". É para isso que nos voltamos a seguir.

\section{$2.4 \mathrm{O}$ caráter polêmico da fórmula}

A polêmica em torno da noção formuláica pode se efetuar, segundo a autora, "ao modo de injunção de proferimento e ao da recusa de enunciar" (KRIEG-PLANQUE, 2010, p. 100) ou pode recair sobre o conhecimento social da mesma (quando se impõe ao espaço público o uso de uma palavra, geralmente em detrimento de uma palavra concorrente). Para a autora, esse caráter polêmico se dá porque ela é tomada nas práticas linguageiras, determinado pelos usos que são feitos dessa sequência, e não somente orientado pela morfossintaxe ou pelos seus componentes lexicais. Assim, um dos meios privilegiados de se estudar uma fórmula consiste em "analisar os diversos tropeços dos locutores no decorrer das sequências ou, dito de outro modo, consiste em analisar as diferentes operações metadiscursivas opacificantes que incidem sobre a fórmula" (KRIEG-PLANQUE, 2010, p. 108).

Para um termo se caracterizar como fórmula, as pessoas, ao se pronunciarem sobre ele, geram polêmica. No caso da colaboração, o discurso e a necessidade de que se defina o que uma dada área entende pelo termo demonstram os diferentes sentidos existentes. Assim, o termo 'colaboração' não é consensual, pois mesmo dentro de uma área há diversos sentidos dados a ele.

A exemplo disso, evidenciamos nos resumos analisados um movimento de adjetivação da colaboração em 'colaboração crítica' de modo a evidenciar a polêmica que pode emergir da multiplicidade dos sentidos do termo. Ao se adjetivar, há um estabelecimento de limites entre essa 'colaboração' das outras mobilizadas, além de se estabelecer novos sentidos à colaboração a partir do seu adjetivo. 


\section{(4)}

[...] discutir a colaboração crítica como uma categoria para compreender o desenvolvimento de uma atividade de formação de professores em contexto virtual. [...] Os resultados mostram que a experiência de colaboração crítica aplicada em contexto virtual vivenciada pelos colaboradores abriu perspectivas ao desenvolvimento de um processo pedagógico virtual plural, acolhedor da contradição estabelecida no diálogo entre os colaboradores como forma de avançar coletivamente, comprometido com a transformação, que se operacionaliza no movimento de um processo histórico e social. (OLIVEIRA, 2009)

Essa discriminação da 'colaboração' é ainda retomada em trabalhos que se delimitam na 'Pesquisa Crítica de Colaboração' que pretende diferenciar-se de outros pronunciamentos sobre a colaboração em termos de método de investigação para a pesquisa escolar, associada a características como o questionamento, resolução de problemas por meio da argumentação, transformação dos papéis dos participantes, normalmente vinculada à teoria sócio histórico-cultural.

(5)

Está fundado na Pesquisa Crítica de Colaboração - PCCol (MAGALHÃES, 2002; 2004 e 2007). [...] Os resultados revelam que: (i) professores e monitores reconstruíram seus sentidos iniciais sobre monitoria; (ii) os papéis de professores e monitores foram ressignificados; e (iii) as ações desenvolvidas na escola apontam para uma nova de organização do contexto de sala de aula. Mostram também a importância da criação de espaços colaborativos no contexto da pesquisa e na escola pública, principalmente na pesquisa de intervenção. (FARIA, 2010).

A polêmica em torno da fórmula 'colaboração', além da multiplicidade de sentidos atribuídos, manifesta-se em trabalhos que confrontam o seu aspecto transformador. 
(6)

A experiência recente de educação a distância utilizando a Internet vem registrando, nos últimos anos, um incremento considerável no apelo a metodologias pedagógicas que enfatizam a colaboração entre os participantes. No entanto, estes processos assíncronos formais, na maioria dos casos, vêm se revelando precários, uma vez que não se mostram efetivamente duradouros e consequentes. (MATTOS, 2005)

No recorte anterior, há o reconhecimento da 'colaboração' no contexto da educação a distância como amplamente presente nos debates da área. No entanto, aponta para uma problemática em razão dos processos que se revelam precários.

Isto evidencia uma polêmica em torno dos instrumentos tecnológicos colaborativos e o tipo de colaboração que se almeja desenvolver. A polêmica mobiliza repensar as dimensões discursivas que atestam as potencialidades da colaboração e das ferramentas colaborativas como aquelas legitimadas dentro desse campo discursivo como a solução para uma transformação/ construção de uma dada realidade.

\section{Considerações e Implicações deste Estudo}

Cientes de que não é qualquer expressão cristalizada que constitui uma fórmula, partimos, neste texto, da hipótese de que o termo 'colaboração' poderia constituir um candidato à noção de fórmula. Com base no referencial de Krieg-Plangue (2010), analisamos este termo a partir de 48 resumos de teses de doutorado desenvolvidas no Brasil de 2005 a 2010, disponibilizadas pelo Banco de Teses da CAPES.

Entendendo que "uma sequência é mais ou menos fórmula conforme preencha mais ou menos cada uma das quatro propriedades que a caracterizam" (KRIEG-PLANQUE, 2010, p. 111) - o que significa dizer que uma fórmula deve revelar-se em seu caráter cristalizado, discursivo, de referente social e polêmico sem que necessariamente todos estejam igualmente presentes ou sejam igualmente preenchidos - esse estudo revela que o termo 'colaboração' pode ser entendido como fórmula porquanto apresente o 
caráter gradual e continuum da fórmula, atendendo as quatro propriedades, de maneira mais ou menos satisfatória.

Com base no pressuposto de que uma fórmula não circula exclusivamente em um determinado espaço social, selecionamos as pesquisas de doutorado como recorte para a análise e, devido ao escopo deste relato, concentramo-nos naquelas próprias da área educacional. É certo que esse recorte não dá conta de mostrar toda dinamicidade, cristalização e polemicidade da fórmula nos seus usos na esfera social. Portanto, uma melhor compreensão pode ser desenvolvida a partir de outros estudos aprofundados da sua circulação e materialização em outros campos discursivos, tais como empresarial, político, bem como a partir de outros gêneros do discurso, para além dos resumos de teses, a exemplo, a sua circulação na mídia.

Por outro lado, ao evidenciarmos seu percurso em práticas discursivas acadêmicas, muitas vezes em forma de sintagma reivindicados por muitos, aquilo que até aqui se mostra nos permite considerar a 'colaboração' como um termo de consenso, mobilizado massivamente e pouco definido, impondo-se, por assim ser, como conceito dominante e consagrado como prática necessária, dada, inexorável e aceitável.

Ao estabelecer a compreensão do caráter formuláico da 'colaboração', esperamos provocar reflexões quanto ao seu movimento nos diversos contextos em que é mobilizada. Acreditamos que, ao imprimir ao conceito um caráter conflituoso e problemático, reconhecendo, explicitando e questionando os contextos sócio-históricos e formações ideológicas que motivam parte de seus usos, podemos criar meios de resistir à utilização esvaziada do termo que, ao final, contribui para a cristalização de questões sócio-políticas-educacionais que, por princípio, o próprio termo deveria questionar.

Certas de que aquilo que torna nosso trabalho de linguistas aplicados um trabalho crítico é a tensão entre uma base ontológica-epistemológicametodológica firme para ação político-social e seu simultâneo questionamento, esperamos que a presente discussão contribua para a problematização dos usos de 'colaboração' e para o reconhecimento das formações discursivas, ideologias e hegemonias às quais nos vinculamos, como pesquisadores. 


\section{Referências}

CHEYNE, A.; TARULLI, D. Dialogue, difference, and the "third voice" in the zone of proximal development. [s.d.]. Disponível em: <http:// webpages.charter.net/schmolze1/vygotsky/bakhtin.html>. Acesso em: 24 jun. 2004.

COLE, M. Cultural psychology: a once and future discipline. Cambridge: Harvard University Press, 1996.

COLE, M.; ENGESTRÖM, Y. A cultural-historical approach to distributed cognition. In: SALOMON, G. (Ed.). Distributed cognition: psychological and educational considerations. Cambridge University Press, 1993. p. 1-46.

ENGESTRÖM, R. Voices as a communicative action. Mind, Culture and Activity, v. 2, n. 3, p. 196-213, 1995.

ENGESTRÖM, Y. Teachers as collaborative thinkers: activity-theoretical study of an innovative teacher team. In: CARLGREN et al. (Eds.). Teachers' minds and actions: research on teachers' thinking and practice. Falmer Press, 1994. p. 43-61.

ENGESTRÖM, Y. Non scolae sed vitae discimus: como superar a encapsulação da aprendizagem escolar. In: DANIELS, H. (Org.). Uma introdução a Vygotsky. Tradução Marcos Bagno. São Paulo: Edições Loyola, 2002 [1996]. p. 175-197.

FAIRCLOUGH, N. Analysing discourse: textual analysis for social research. London; New York: Routledge, 2003.

FARIA, J. P. A monitoria na escola pública: sentidos e significados de professores e monitores. 2010. Tese (Doutorado em Linguística Aplicada e Estudos da Linguagem) - Pontifícia Universidade Católica de São Paulo, São Paulo. 2010.

HASAN, R. Semiotic mediation, language and society: three exotropic theories Vygotsky, Halliday and Bernstein. [s.d.]. [mimeo.]

HOLZMAN, L. H. Pragmatismo e materialismo dialético no desenvolvimento da linguagem. In: DANIELS, H. (Org.). Uma introdução a 
Vygotsky. Tradução Marcos Bagno. São Paulo: Edições Loyola, 2002 [1996]. p. 83-109.

JOHN-STEINER, V. Creative collaboration. New York: Oxford University Press, 2000.

JÚNIOR, A. T. Formação de formadores de professores de matemática: identificação de possibilidades e limites da estratégia de organização de grupos colaborativos. 2006. Tese (Doutorado em Educação Matemática) - Pontifícia Universidade Católica de São Paulo, São Paulo. 2006.

KRIEG-PLANQUE, A. A noção de "fórmula" em análise do discurso - quadro teórico e metodológico. Tradução Salgado e Possenti. São Paulo: Parábola, 2010.

MAINGUENEAU, D. A Análise do Discurso e suas fronteiras. Matraga, Rio de Janeiro, v. 14, n. 20, p.13-37, jan./jun. 2007.

MATTOS, F. L. C. L. Concepção e desenvolvimento de uma abordagem pedagógica para processos colaborativos a distância utilizando a internet. 2005. Tese (Doutorado em Educação) - Universidade Federal do Ceará, Fortaleza. 2005.

MOURA, M. G. C. Teorizando a prática, construindo a teoria, um diálogo com a incerteza: desafios para o professor da educação de jovens e adultos. 2006. Tese (Doutorado em Educação) - Universidade Federal do Rio Grande do Norte, Natal. 2006.

OLIVEIRA, A. L. A. M. Hermes e bonecas russas: um estudo colaborativo para compreender a relação teoria-prática na formação docente. 2006. Tese (Doutorado em Estudos Linguísticos) - Universidade Federal de Minas Gerais, Belo Horizonte. 2006.

OLIVEIRA, W. A colaboração crítica no desenvolvimento de uma atividade de formação de professores a distância. 2009. Tese (Doutorado em Linguística Aplicada e Estudos da Linguagem) - Pontifícia Universidade Católica de São Paulo, São Paulo. 2009.

PARDO-ABRIL, N. G. Cómo hacer análisis crítico del discurso: una perspectiva latinoamericana. Santiago de Chile: Frasis, 2007. 
PAULA, L. G. Uma pesquisa colaborativa com duas professoras universitárias de inglês: entraves e mudanças. 2010. Tese (Doutorado em Letras e Linguística) - Universidade Federal de Goiás, Goiânia. 2010.

ROGOFF, B. The cultural nature of human development. Oxford University Press, 2003.

VILLALOBOS, A. P. O. Aprendizagem colaborativa mediada pela tecnologia no curso de formação de tutores em EAD. 2007. Tese (Doutorado em Educação) - Universidade Federal da Bahia, Salvador. 2007.

VOSS, J. A propoìsito das nocopes de foìrmula e de percurso para a anailise de discurso. Revista Prolíngua, v. 6, n. 1, p. 15-24, jan./jun. 2011.

VYGOTSKY, L. S. Interaction between learning and development. In: COLE, M. et. al. (orgs.). Mind in society. Cambridge: Cambridge University Press, 1978 [1930].

VYGOTSKY, L. S. The collected works of L.S. Vygotsky, volume 4: The history of the development of higher mental functions. New York; London: Plenum Press, 1997.

VYGOTSKY, L. S. A formação social da mente: o desenvolvimento dos processos psicológicos superiores. 6. ed. Tradução José Cipolla Neto et al. São Paulo: Martins Fontes, 1998.

VYGOTSKY, L. S. The collected works of L. S. Vygotsky, volume 6: Tool and sign in the development of the child. New York: Plenum Press, 1999. 